\title{
Spark ablation inductively coupled plasma mass spectrometry analysis of minor and trace elements in low and high alloy steels using single calibration curves
}

\author{
R. Maibusch, ${ }^{a}$ H.-M. Kuss, ${ }^{a}$ A. G. Coedo, ${ }^{* b}$ T. Dorado ${ }^{b}$ and I. Padilla ${ }^{b}$ \\ ${ }^{a}$ University Duisburg, Lotharstrasse 1, 47057 Duisburg, Germany \\ ${ }^{b}$ CENIM (CSIC), Gregorio del Amo, 8.28040 Madrid, Spain
}

Received 1st March 1999, Accepted 2nd June 1999

\begin{abstract}
A unidirectional high current pulse spark with a very fast rise-time, ensuring a rapid and complete transfer of energy to the sample, was used as the sampling system for the analysis of carbon steels and highly alloyed steels with the same operating conditions. The sparking operating conditions were optimised and a restrictive path was designed to decrease the quantity of eroded material reaching the plasma, in order to prevent deposition of material in the torch injector, and to minimise sampling cone blockage and drift effects. Spark ablation sampling efficiency and effectiveness of the restrictive path were evaluated. To compensate for differences in the amount of material ablated or for a variation in drift, ${ }^{57} \mathrm{Fe}$ and ${ }^{55} \mathrm{Mn}$ were used as internal standards. The calibration procedure was applied to the analysis of the elements $\mathrm{Al}, \mathrm{B}, \mathrm{Co}, \mathrm{Cu}, \mathrm{Mn}, \mathrm{Nb}, \mathrm{P}, \mathrm{Si}$, and $\mathrm{V}$, present in the following certified reference materials: BCS (Bureau of Analysed Samples) SS-456 to SS-460 (residual series); CRMs (European Committee for Iron and Steel Standardisation) No 285-2 (Maraging steel), No 292-1 (niobium stabilised steel), No 295-1 (highly alloyed steel), and No 296-1 (jethete steel). When plotting intensity ratios $\left(I_{\mathrm{X}} / I_{\mathrm{IS}}\right)$ versus concentration ratios $\left(C_{\mathrm{X}} / C_{\mathrm{IS}}\right)$ linear calibration curves over the entire range of tested concentrations, with correlation coefficients better than 0.999 , were obtained. Determination limits below $1 \mu \mathrm{g} \mathrm{g}^{-1}$ were found and the precision was better than $2.8 \%$. It has also been shown to determine carbon contents at concentration levels greater than $0.03 \%$ with RSD values below 3\%. For the elements As, Sn, Ti, W and Zr, only present in one or two of the Standard Materials, the sensitivity was also evaluated. Furthermore, the possibility of obtaining reproducible transient signals from sparking periods of only a few seconds was demonstrated.
\end{abstract}

\section{Introduction}

When analysing solids, conventional inductively coupled plasma based spectrometry (ICP-AES and ICP-MS) has always been slowed down by the need to dissolve the sample. If a spark source, however, is coupled to the ICP torch, electrically conductive samples can be directly analysed. In spark ablation (SA) the sample acts as a cathode positioned above a tungsten counter electrode and the sparking source generates particles transported into the plasma (ICP), where atomisation and ionisation occur. Spark ablation, in the case of bulk analysis of metals, has received attention from different research groups for possible use in ICP (whether by emission spectroscopy or mass spectrometry). In its earliest version Human et al. ${ }^{1}$ used a high voltage spark with ICP-AES and they found curved calibration graphs which related to the evaporation behaviour of some of the particles. Aziz et al. ${ }^{2}$ maintained that the use of a high repetition source at medium voltage delivered a fine aerosol, which allowed the transportation and effective excitation in an analytical ICP. Lemarchand et al. ${ }^{3}$ showed that for ferrous alloys the power of detection of spark erosion as the sampling technique in ICP-AES is similar to that of direct spark emission spectrometry and also showed its feasibility for the direct analysis of high alloyed steels by determining nickel in some standard reference materials. Vujicic and Steffan ${ }^{4}$ applied the technique to the analysis of free cutting steels. They performed a comparison of spark emission, spark-ICP-AES and continuous nebulization-ICP-AES for the analysis of standard materials, concluding that the results provided by the different methods were comparable. Coedo et al. ${ }^{5}$ reported the analytical performances obtained with spark OES, ICP with pneumatic nebulization and spark ablation ICP-OES for the determination of $\mathrm{Al}, \mathrm{Ti}, \mathrm{Nb}$ and $\mathrm{V}$ in low alloyed steels. The limits of detection (LOD) obtained with SA-ICP-OES were comparable to liquid nebulization and five times lower than those obtained from spark-OES. Webb et al. ${ }^{6}$ used a novel electronic spark source for direct solid sampling with ICP-OES, obtaining detection limits in the single digit ppm range. Gagean and Mermet $^{7}$ compared ultraviolet laser ablation and spark ablation of metals and alloys for analysis by axially viewed ICP-AES, concluding that both systems provide good sensitivity.

When ICP-MS uses the preparation of a solution from the solid test sample, the procedure is always a source of contamination as well as of polyatomic interferences, produced by the elements present in the reagents; therefore, the interest in direct introduction techniques for solid samples in ICP-MS is increasing. Jiang and $\mathrm{Houk}^{8}$ applied an arc nebulization for elemental analysis of conducting solids by ICP-MS. Jakubowski et al. $^{9}$ applied this technique to the analysis of the NIST SRMs Series 1162 to 1165, obtaining detection limits below $100 \mathrm{ng} \mathrm{g}^{-1}$. Ivanovic et al. ${ }^{10}$ observed a direct linear relationship between electron multiplier counts and concentration for trace elements in a series of pure copper standards, without requiring either concentration normalisation or internal standardisation procedures. Investigations of Kuss et al. ${ }^{11}$ have shown that spark ablation ICP-MS is a very good alternative to liquid analysis, especially for the elements that are critical to analyse because of the interferences caused by 
the acid solutions (e.g., $\mathrm{P}$ and $\mathrm{Si}$ ). Coedo et al. ${ }^{12}$ used a SA-ICP-MS for the simultaneous determination of residual elements in low alloyed steels and found that the detection limits were comparable to those obtained with continuous nebulization, concluding that SA-ICP-MS is a valid sampling system for the simultaneous determination of $\mathrm{P}, \mathrm{Si}, \mathrm{Mn}, \mathrm{Al}$, $\mathrm{V}, \mathrm{B}, \mathrm{Co}, \mathrm{Zr}$ and $\mathrm{Sb}$ in low alloy steels. A comparison of the performance of spark ablation ICP-MS and glow discharge mass spectrometry (GDMS) for direct element analysis of conductive solids was carried out by Jakubowski et al., ${ }^{13}$ showing that spark ablation should therefore be considered as a promising and powerful option for the direct element analysis of solids. Borisov et al. ${ }^{14}$ applied the technique to the determination of $\mathrm{V}, \mathrm{Rh}$ and $\mathrm{Pt}$ in automotive catalytic converters, obtaining very encouraging preliminary results.

The purpose of this paper is to develop a procedure for the determination of residual elements in carbon steels and highly alloyed steel by SA-ICP-MS, under the same operating conditions. One goal of the study was to design the transfer line between the sparking cell and the torch in order to decrease the quantity of material reaching the plasma, maintaining a good sensitivity and reproducibility. The improvement of precision and accuracy of the analytical data was achieved by the use of ${ }^{57} \mathrm{Fe}^{+}$and ${ }^{55} \mathrm{Mn}^{+}$as internal standards. Furthermore, tests were carried out to evaluate the possibilities of the system to also determine the carbon content of the selected samples.

\section{Experimental}

\section{Instrumentation}

An ELAN 6000 ICP-MS (Perkin-Elmer SCIEX, Thornhill, ON, Canada) with a SPARK 10 (Varian Techtron, Mulgrave, Victoria, Australia) as sampling device was used. The ICP-MS and the SPARK operating conditions are listed in Table 1. The spray chamber from the ICP-MS was removed and the eroded material was carried by an Ar flow through a Tygon

Table 1 Operating conditions for ELAN 6000 and SPARK 10

\begin{tabular}{|c|c|}
\hline \multicolumn{2}{|l|}{ ELAN 6000- } \\
\hline Rf power/W & 1200 \\
\hline Plasma Ar flow $/ 1 \mathrm{~min}^{-1}$ & 15 \\
\hline Nebulizer Ar flow $/ 1 \mathrm{~min}^{-1}$ & 0.70 \\
\hline Analog stage voltage & -2000 \\
\hline Pulse stage voltage & 1350 \\
\hline $\begin{array}{l}\text { Mass spectrometer running } \\
\text { pressure } / \mathrm{Pa}\end{array}$ & $3.68 \times 10^{-5}$ \\
\hline Dwell time per analyte/ms & 200 \\
\hline Dwell time for ${ }^{57} \mathrm{Fe} / \mathrm{ms}$ & 2 \\
\hline Dwell time for ${ }^{55} \mathrm{Mn} / \mathrm{ms}$ & 4 \\
\hline Sweeps per reading & 5 \\
\hline Readings per replicate & 1 \\
\hline Number of replicates & 3 \\
\hline Analytes & $\begin{array}{c}{ }^{11} \mathrm{~B}^{+},{ }^{12} \mathrm{C}^{+},{ }^{27} \mathrm{Al}^{+},{ }^{31} \mathrm{P}^{+},{ }^{28} \mathrm{Si}^{+}, \\
{ }^{75} \mathrm{Ti}^{+},{ }^{51} \mathrm{~V}^{+},{ }^{59} \mathrm{Co}^{+},{ }^{63} \mathrm{Cu}^{+}, \\
{ }^{184} \mathrm{~W}^{+},{ }^{90} \mathrm{Zr}^{+},{ }^{93} \mathrm{Nb}^{+},{ }^{120} \mathrm{Sn}^{+}\end{array}$ \\
\hline Internal standards & ${ }^{55} \mathrm{Mn}^{+},{ }^{57} \mathrm{Fe}^{+}$ \\
\hline Integration time per analyte $/ \mathrm{ms}$ & 1000 \\
\hline Integration time for ${ }^{57} \mathrm{Fe} / \mathrm{ms}$ & 10 \\
\hline Integration time for ${ }^{55} \mathrm{Mn} / \mathrm{ms}$ & 20 \\
\hline Scanning mode & Peak hopping \\
\hline Estimated sample reading/s & 42 \\
\hline Read delay/s & 15 \\
\hline \multicolumn{2}{|l|}{$S P A R K 10-$} \\
\hline Pre-spark and spark conditions & $\begin{array}{l}\text { Frequency, } 500 \mathrm{~Hz} \text {; current, } \\
\quad 60 \mathrm{~A} \text {; pulse, } 8 \mu \mathrm{s}\end{array}$ \\
\hline Spark transport-flow $/ 1 \mathrm{~min}^{-1}$ & 1.4 (axial, $1.0 ;$ auxiliary, 0.4 ) \\
\hline Timing/s & Pre-spark, 50; spark, 40 \\
\hline Tip gap $/ \mathrm{mm}$ & 3 \\
\hline
\end{tabular}

tube into the injector of the ICP torch. A valve system and a transfer path were applied to improve the line connection between the sparking cell and the ICP. Fig. 1 shows a scheme of the complete system with the valves system and the transfer path included.

\section{Standards and calibration samples}

Two standard samples, CENIM C-305 (carbon steel) and C-317 (stainless steel) were used for optimisation of the system. The Certified Reference Materials BCS (Bureau of Analysed Samples) SS-456 to 460 (residual series) and CRM (European Committee for Iron and Steel Standardisation) No. 285-2 (Maraging steel), No. 292-1 (niobium stabilised steel), No. 295-1 (highly alloyed steel) and No. 296-1 (jethete steel) were used within the calibration curves. Pure iron Standard Reference Material BAM 098/1 was used for background and for determination limits calculation. The samples in a discshaped form were finished to a clean uniform surface by using a surface grinder with 60 -grit abrasive finer zirconium oxide belt in an abrading device.

\section{Discussion}

\section{Sparking}

In spark ablation ICP spectrometry, the sample serves as the cathode. A high melting-point tungsten anode is used to provide a high voltage, and high frequency, unidirectional spark. The material ablated from the cathode is transported by an argon flow to the ICP where the ionisation takes place. The spark device used was developed firstly for application in ICP-AES, and to be applied in ICP-MS some modifications had to be made in order to minimise the mass of eroded material reaching the plasma along an entire sampling sequence (pre-spark, read time delay and measurement), thus minimising the risk of cone blockage and drift effects.

To satisfy the above objective two main modifications were introduced: namely, a valve system and a restrictive path.

The valve system (controlled manually, or automatically by the Spark Timer) was set up in order to make possible the separation of the pre-spark gas stream from the spark gas stream. With this modification, during the pre-sparking time (St1) the eroded material flows to the waste, and only during the analyses time ( $\mathrm{St} 2)$ does the sample reach the plasma. In order to maintain the plasma conditions constant during the pre-sparking time, an additional Ar stream (with a flow rate similar to that used for sampling transport) was introduced through the nebulizer flow. Furthermore, this system offers the possibility of regulating (for periods of a few seconds) the time during which the sample reaches the plasma, thus providing a transient signal. At the end of each sparking process a flushing step was applied to clean the system; during this step the gas flow is again diverted to waste. Before analysing a new sample the anode was always cleaned with a wire brush.

Moreover, because of the high sensitivity of the technique and its low tolerance to the size of particles reaching the plasma, several restricted paths were tested. The effectiveness of the different restrictive devices in removing large eroded particles from the Ar stream was evaluated by trapping the particles during a fixed period of $5 \mathrm{~min}$ in a $5 \%(1+3) \mathrm{HCl}-$ $\mathrm{HNO}_{3}$ acid solution, at different points in the transfer line. Subsequently, after heating the solutions their Fe content was determined by ICP-AES. This determination was carried out before evaluating the optimum sparking operating conditions to be sure that during the optimisation process no excessive quantity of particles reached the plasma. For these preliminary tests the sparking conditions applied were: $500 \mathrm{~Hz}, 40 \mathrm{~A}$ and a pulse rate of $8 \mu \mathrm{s}$ (recommended conditions in the Varian SPARK 10 manual for the analysis of low alloy steels by ICP- 


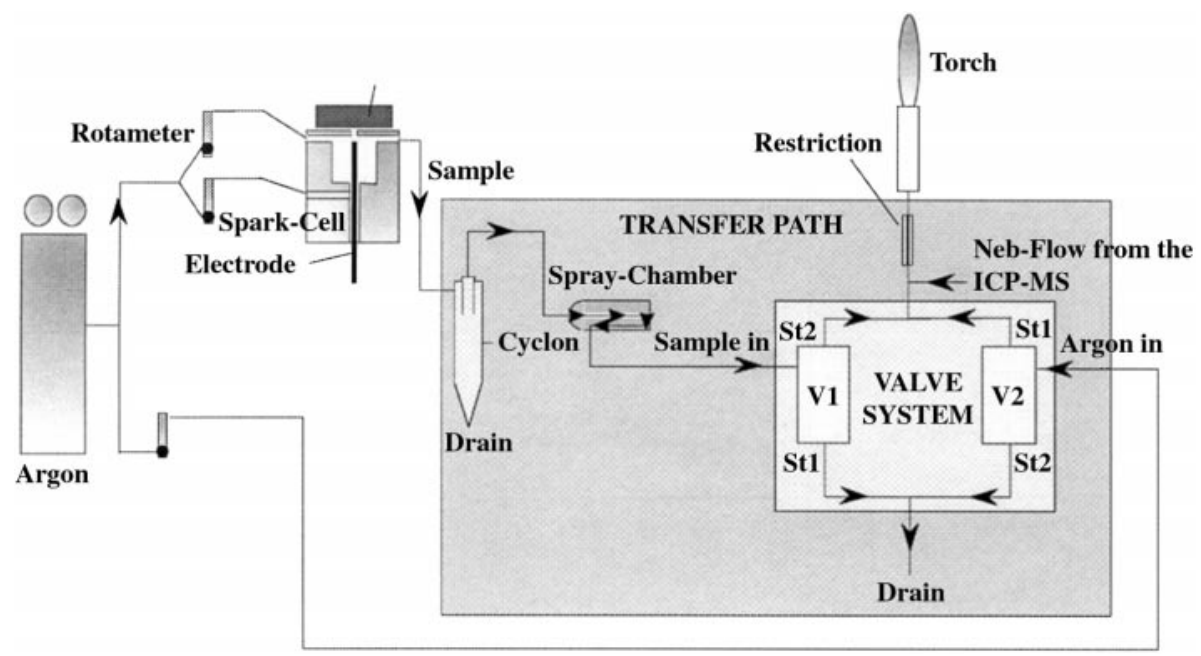

Fig. 1 Schematic diagram of the whole sampling system. St 1, sample to drain and Ar to plasma (during pre-spark). St 2, sample to plasma and Ar to drain (during analysis).

Table 2 Evaluation of the quantity of sample present at different points of the transfer line (average of six sparking processes of $5 \mathrm{~min}$ each from sample C-305, $99 \% \mathrm{Fe})$

\begin{tabular}{lll}
\hline Sampling point & Fe $/ \mu \mathrm{g} \mathrm{min}$ & Relative Fe value $(\%)$ \\
\hline A (after the sparking cell) & $9.8 \pm 1.0$ & 100 \\
B (after 1 cyclon) & $7.0 \pm 0.8$ & 70 \\
C (after 2 cyclons) & $3.0 \pm 0.5$ & 30 \\
D (after 2 cyclons and a & $1.0 \pm 0.1$ & 10 \\
$\quad$ restriction) & & \\
\hline
\end{tabular}

AES). Table 2 shows the contents of Fe found at different points in the transfer line, from six different sparking processes ( 5 min each) applied to the sample C-305 (carbon steel). To better compare the $\mathrm{Fe}$ quantity, the amount found just after the sparking cell $\left(9.8 \mu \mathrm{g} \mathrm{min}^{-1}\right)$ has been considered as $100 \%$. Assuming that the aqua regia trapping efficiency could be considerably lower than $100 \%$, it can be expected that without using any type of restrictive device more than $10 \mu \mathrm{g}$ of sample per min would arrive in the ICP. Different highly alloyed steels were sampled with the same sparking conditions and the further analysis of the major constituents by ICP-AES showed that the total amount of eroded material does not differ significantly for low or high alloy steels. The mass of sample reaching the plasma was decreased by approximately 10 times with the transfer line designed, thus maintaining a good sensitivity and minimising solid deposition at the injector and the orifices of the cones. A cyclone, used as the first restrictive device, was installed just after the spark chamber. This device operates by imparting a spiral motion to the aerosol, as a result of which, and owing to the higher angular momentum, particles of larger diameter tend to impact on the walls of the chamber and therefore do not reach the plasma. The design and dimensions of the cyclone have been presented in a previous paper. ${ }^{12}$ In this work and because of the higher efficiency of the sparking system and the higher sensitivity of the ICP-MS instrument compared with those used in the previous work, it has become necessary to redesign the transfer line between the spark cell and the plasma torch, adding new restrictive elements (including a Varian spray-chamber). Fig. 1 shows the complete restrictive path. An additional carrier gas flow (which can be optimised by the ICP-MS software) was added before the restrictive device in order to keep the total gas flow arriving at the plasma at an optimum value.

\section{Selection of sparking conditions}

The sparking operating parameters were optimised in order to make it possible to analyse carbon steels and high alloy steels with the same sparking conditions. To carry out this optimisation process, different combinations of the three variable sparking parameters (frequency, current and pulses) were applied. To evaluate their efficiency the intensities of the isotopes ${ }^{12} \mathrm{C}^{+},{ }^{51} \mathrm{~V}^{+},{ }^{55} \mathrm{Mn}^{+},{ }^{57} \mathrm{Fe}^{+}$and ${ }^{184} \mathrm{~W}^{+}$, as well as the corresponding $\mathrm{RSD}$, were monitored.

The above isotopes were selected, as elements to be monitored, for different reasons: ${ }^{12} \mathrm{C}^{+}$was examined because a good precision in $\mathrm{C}$ signals should indicate that all the carbides present in the sample were homogeneously destroyed; ${ }^{51} \mathrm{~V}^{+}$was chosen because of the difficulty in determining it when using solutions containing $\mathrm{HCl}$, due to polyatomic interferences; ${ }^{55} \mathrm{Mn}^{+}$was monitored because it is usually present in steel samples at relatively high concentrations, therefore being easily quantified for use as an internal standard; ${ }^{57} \mathrm{Fe}^{+}$isotope (abundance: $2.19 \%$ ) was selected to control the main matrix element because the lowest abundance $\mathrm{Fe}$ isotope $\left({ }^{58} \mathrm{Fe}^{+}\right.$, abundance: $0.33 \%$ ) could not be used because of the isotopic interference produced by ${ }^{58} \mathrm{Ni}^{+}$(67.84\% of abundance); finally, ${ }^{184} \mathrm{~W}^{+}$was selected because it was found more difficult to achieve low RSD values for it, compared with the other elements studied. Fig. 2 shows (for sample 305) the $\mathrm{W}$ and $\mathrm{Mn}$ intensity dependence versus frequency (at a pre-fixed current input) and versus current (at a pre-fixed frequency). The rest of the analytes present a similar behaviour. The use of higher spark energies (leading to a higher ablation rate) is not only limited by the molten effect, but also by the risk of instability due to flickering in the ICP and by the increase of drift effects (produced by the clogging of cones and tubes). Furthermore, there is no guarantee that the particles are completely vaporised in the ICP and consequently better sensitivity is not always achieved. From the values obtained and taking into consideration the need for both a good sensitivity and a satisfactory stability, the selected electrical operating parameters were $500 \mathrm{~Hz}$ and $60 \mathrm{~A}$. These conditions are similar to those applied by Webb et al. ${ }^{6}$ in ICPAES, without using any restrictive device. Borisov et al. ${ }^{14}$ also used a high voltage source, and they found a similar behaviour for the signal intensity versus frequency and current, with optimal results at repetition rates of $2000 \mathrm{~Hz}$ and a current of $30 \mathrm{~A}$. However, they found lower precision at higher current intensity values, which can be explained by the fact that they only used one spray chamber and so the effectiveness of 


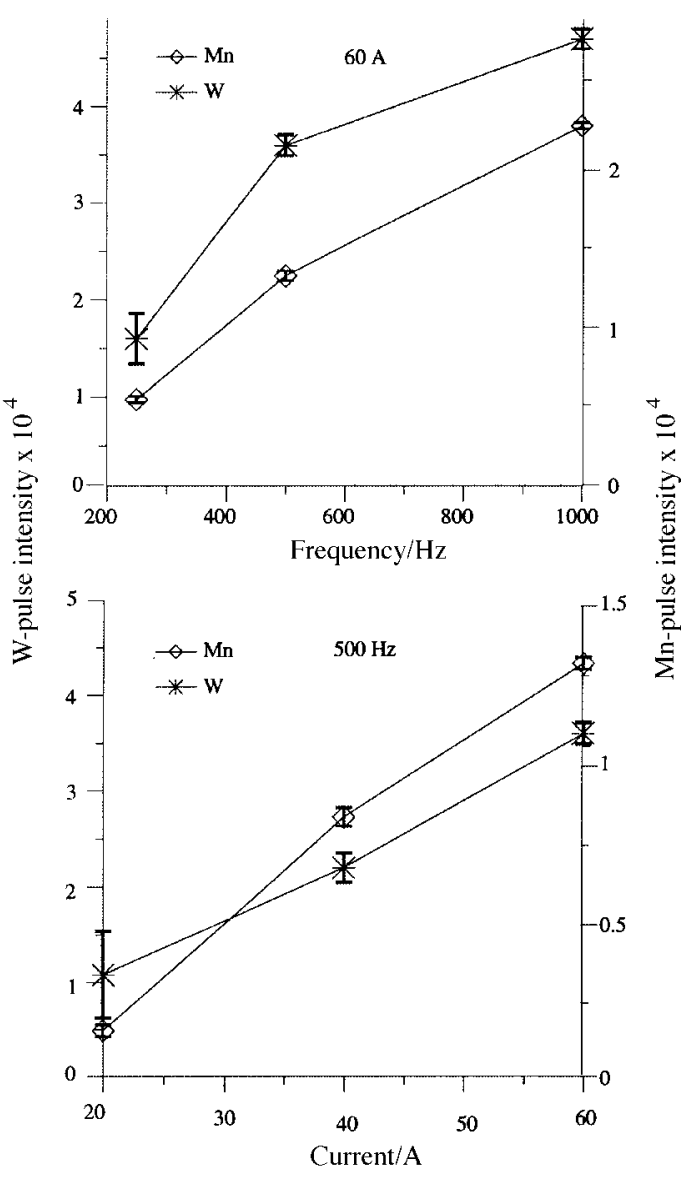

Fig. $2 \mathrm{~W}$ and $\mathrm{Mn}$ intensity dependence versus frequency and current.

removing the bigger particles (which cause flickering in the ICP) is much lower in comparison with the transfer path used in this work.

The burning spots show that a partial melting process occurs; further, a partial re-deposit of the ablated material at the edge of the burn spot could be observed. Fig. 3 (A, B and C) shows photographs of the spot surface in sample C-305, after applying different current values at a pre-fixed frequency of $500 \mathrm{~Hz}$. As can be observed, the more energetic the spark, the more significant are the melting areas. It may be assumed that extended melting areas give rise to condensates of metallic vapor, formed by evaporation from the molten phase, that could play an uncontrolled role during the ablation process. Fig. 4 shows the SEM spectra from the outer, black zone and from the inner, central zone of the burning crater, obtained with the selected sparking parameters; as can be seen the oxygen signal is significantly higher in the black outer zone, which could be explained by the faster oxidation of the condensed metal at the edge of the burn.

The argon transport flow rate used was $1.41 \mathrm{~min}^{-1}$ and an additional carrier gas flow (the nebulizer gas flow of the ICP-MS, optimised by the ICP-MS software) of about $0.71 \mathrm{~min}^{-1}$ was added before the restriction system. Thus, the Ar flow (after the restriction) reaching the plasma was about $0.751 \mathrm{~min}^{-1}$, and this provided efficient sample transport and plasma stability. By the above monitored optimised sparking conditions, carbon steel samples and highly alloyed steel samples can be analysed with good sensitivity and stability. Plots of continuous measurements for ${ }^{12} \mathrm{C}^{+},{ }^{51} \mathrm{~V}^{+},{ }^{55} \mathrm{Mn}^{+}$, ${ }^{57} \mathrm{Fe}^{+}$and ${ }^{84} \mathrm{~W}^{+}$are shown in Fig. 5 for samples C-305 (carbon steel, 98\% Fe) and C-317 (high alloyed steel, 70\% Fe). As the isotopes ${ }^{55} \mathrm{Mn}^{+},{ }^{57} \mathrm{Fe}^{+}$were measured with reduced integration time (Table 1) sensitivity cannot be compared using the plotted intensity values (counts); this comparison can only

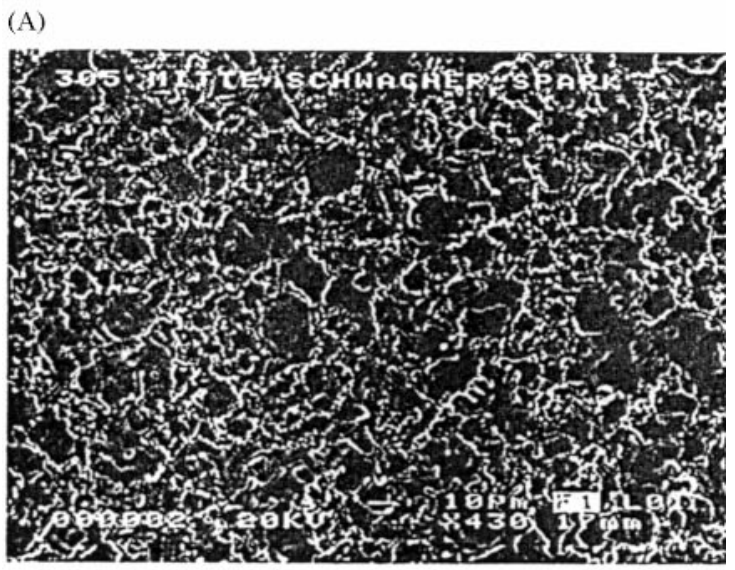

(B)
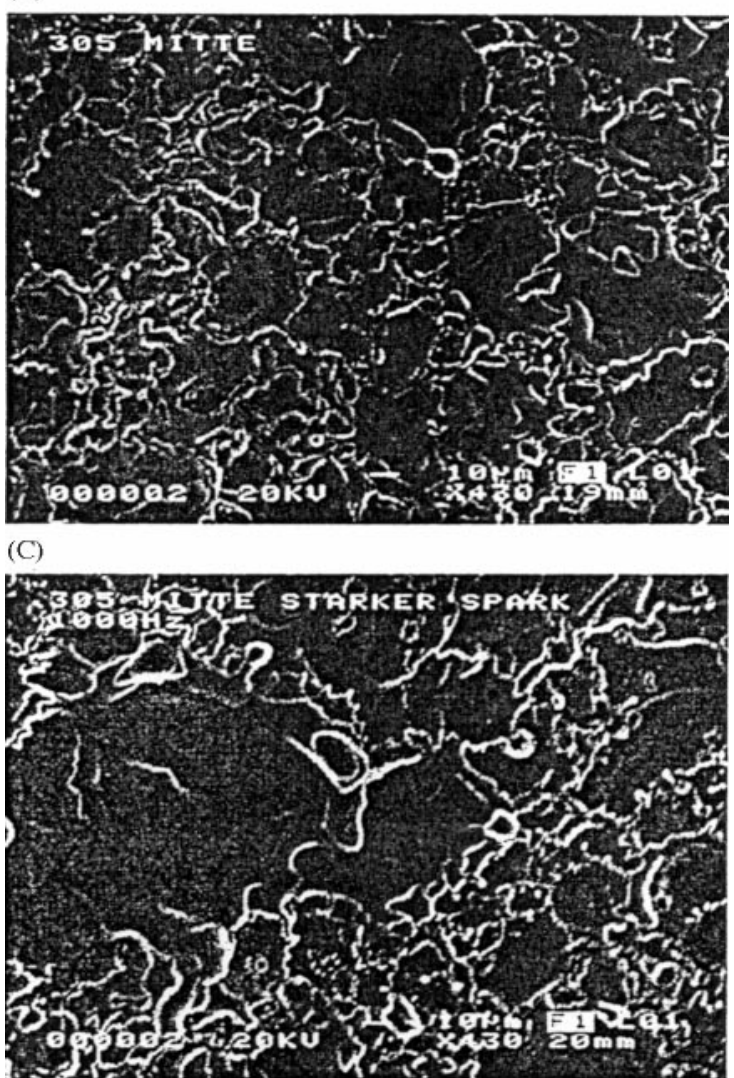

Fig. 3 Photographs of the spot surface in sample C-305. Frequency $500 \mathrm{~Hz}$ and different current values. (A) $20 \mathrm{~A}$; (B) $60 \mathrm{~A}$; (C) $80 \mathrm{~A}$.

be made when counts $\mathrm{s}^{-1}$ are used. For a majority of elements the signal intensities reached a steady-state after approximately $20 \mathrm{~s}$; nevertheless the best stability for all the tested elements ( RSD values $<2.8 \%$ ) was obtained by using a pre-sparking time of $50 \mathrm{~s}$. After the pre-sparking period, and for quantitative measurements, a time reading delay of $15 \mathrm{~s}$ was applied in order to allow the sample to reach the torch and the plasma to be stabilised (this reading delay is the time elapsed between the pre-spark period and the beginning of the data acquisition). According to the stabilised operating conditions (Table 1), the ICP-MS measurement period was $42 \mathrm{~s}$. Thus, the duration of a SA-ICP-MS process including pre-sparking, read delay and measurement was about $107 \mathrm{~s}$. As can be observed, the signal intensities still remain stable for a longer time (Fig. 5).

\section{Mass spectra}

The intensities of the background spectrum in the range $\mathrm{m} / \mathrm{z}$ $10-80$ were considerably lower than those of aqueous nebulized 


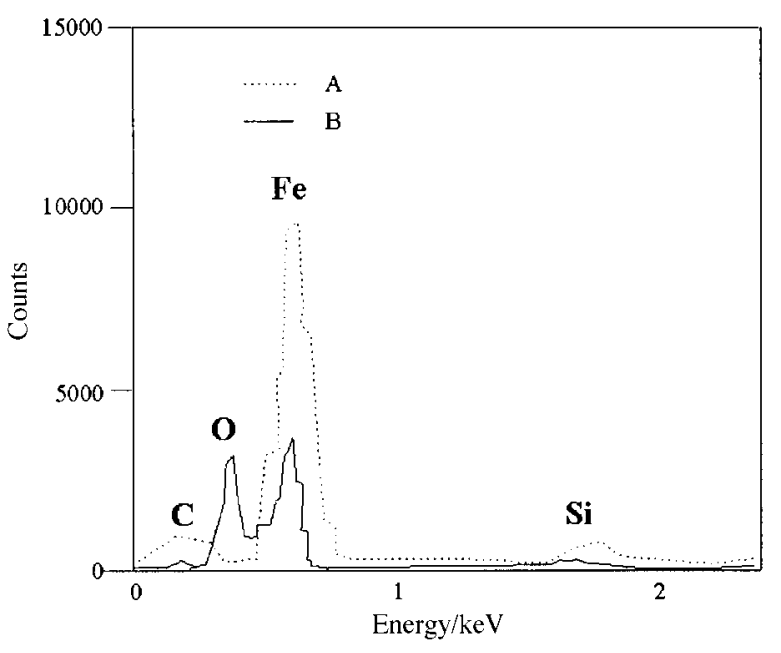

Fig. 4 SEM spectra. A, From the middle of the spark spot; B, from the outer black zone of the spark spot.

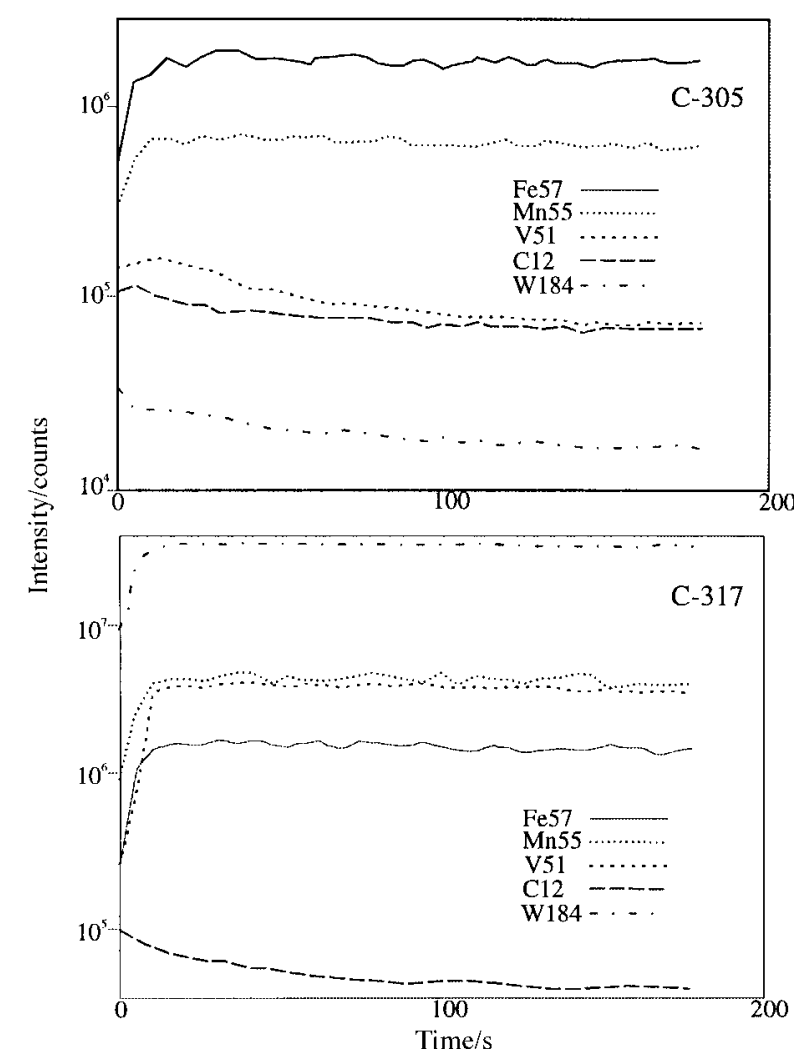

Fig. 5 Time profile measurements for samples C-305 and C-317.

solutions containing mineral acids, especially when $\mathrm{HCl}$ was present. Using this direct sample introduction technique the determination of $\mathrm{V}$ and As is very efficient, as there is no interference from $\mathrm{ClO}^{+}$and $\mathrm{ArCl}^{+}$. Fig. 6 shows comparatively the background spectrum of those elements yielding high background values with liquid nebulization for spark ablation and for acid nebulization. Tests were carried out to study the possibility of $\mathrm{C}$ determination. As significant peaks from ${ }^{12} \mathrm{C}^{+}$were observed it should be noted that it is recommended to use argon of higher purity, as $\mathrm{C}$ might be present as an impurity in argon used for normal ICP analysis. Nevertheless, measurements conducted with the purest $\mathrm{Ar}$ quality available $(99.999 \%)$ indicate that the $\mathrm{C}^{+}$ion only partially arises from $\mathrm{C}$ impurity in Ar; this verifies the theory of Jakubowski et al. ${ }^{13}$ about the presence of contaminant gases diffusing into the plasma from the atmosphere. The BEC (background equivalent concentration) value related to an $\mathrm{Ar}$ purity of $99.995 \%$ was about $0.1 \%$; this value increases to $20 \%$ in the case of the purest quality argon $(99.999 \%)$.

\section{Transient signals}

As was pointed out above, the valve system introduced offers the possibility of regulating (for a few seconds) the time at which the sample reaches the plasma, in order to get a transient signal. Fig. 7 shows the transient peaks obtained from sample C-305 by opening the valve for 2, 5, 10 and $15 \mathrm{~s}$, respectively. It can be seen that from 2 to $5 \mathrm{~s}$ the peak height increases proportionally for all the elements and remains constant thereafter, but peak area continues to rise proportionally. The relative standard deviation of the $\mathrm{Fe}$ and $\mathrm{Mn}$ intensity values, obtained from four $10 \mathrm{~s}$ sparking spots with $10 \mathrm{~s}$ period delays between the spots, were 2.1 and $1.9 \%$, respectively. The clean out time was very short and the background value was achieved in a few ms.

\section{Internal standard}

Calibration is one of the most important aspects of spark ablation ICP-MS and it is a limiting factor for quantitative analysis. If standard reference materials with physical properties and chemical matrices similar to the unknown samples are available, and the drift effects are not significant, quantitative data may be obtained from the net intensity values. When the curves are plotted using the net intensities of the analyte, the scattering of the different calibration samples may reflect either a difference in the amount of material ablated or poor reference data for the calibration samples. Degradation in accuracy and precision can be also produced by uncontrolled variations in working conditions as well as by drift effects due to the inevitable partial cone blockage. To compensate for these negative effects internal standardisation may be used. Any constituent of the sample which is present at a constant or at a known amount in each of the analysed samples can be used as an internal standard. It should also provide a reasonable intensity value, avowing that counting statistics are a limiting factor and ensuring reasonable ratio values. ${ }^{15}$ If an internal standard (IS) at a constant amount in all the samples is used (as it is in the case of using a Fe isotope as IS for analysing any analyte in carbon steel samples, Fe content $>99 \%$ ) the calibration curves are plotted referring the ratio intensities of the analyte to the IS versus the analyte concentration. If the selected IS is not present at a constant amount in all the samples (as happens with the constituents in the high alloyed steels) its concentration must be exactly known in each sample and the calibration curves must be plotted according to the following function; ${ }^{16}$

$$
I_{\mathrm{X}} / I_{\mathrm{IS}}=\mathrm{f} C_{\mathrm{X}} / C_{\mathrm{IS}}
$$

where $I_{\mathrm{X}}$ is the intensity of the analyte, $I_{\mathrm{IS}}$ the intensity of the internal standard, $C_{\mathrm{X}}$ the concentration of the analyte, and $C_{\mathrm{IS}}$ the concentration of the internal standard. In this work ${ }^{57} \mathrm{Fe}^{+}$and ${ }^{55} \mathrm{Mn}^{+}$were used as IS. Fe was selected because it is the main matrix element and consequently the most common IS used to analyse $\mathrm{Fe}$ alloys (especially in spark-OES). Nevertheless, when analysing high alloyed steels with $\mathrm{Fe}$ as the internal standard it is necessary to know the complete elemental composition of the samples in order to calculate (by difference to 100) the real Fe content. Mn was used as IS for two reasons, firstly as it is easy to analyse with any analytical technique, and secondly because it is always present in steel samples, producing intensity values allowing reasonable ratio values. 


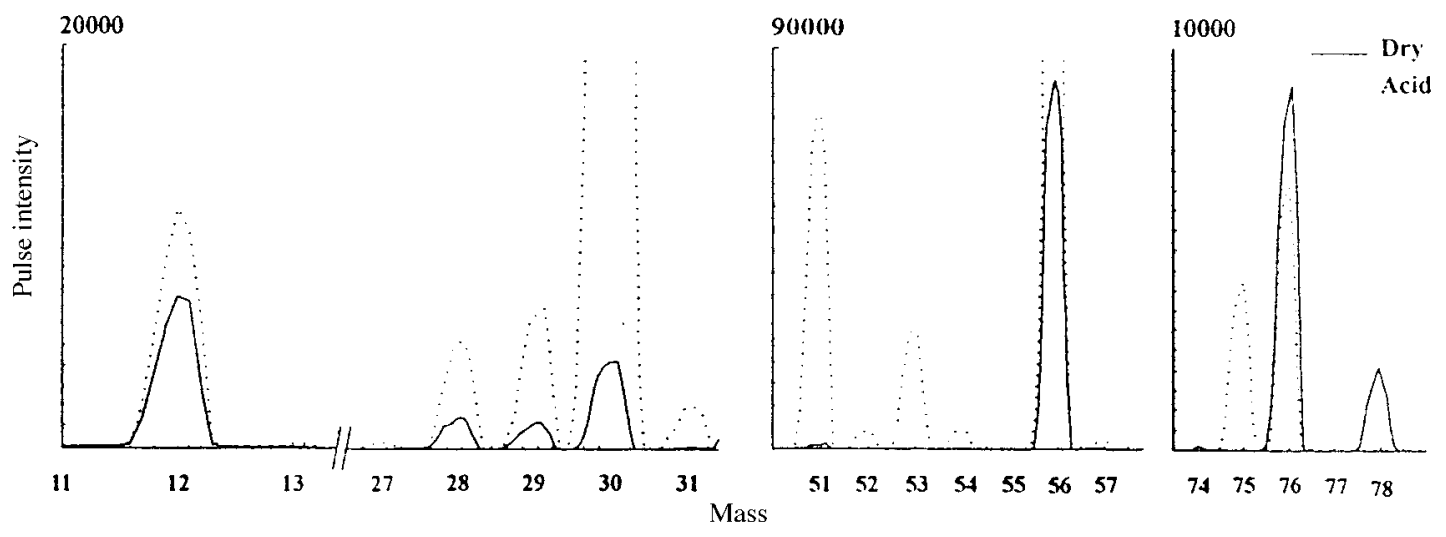

Fig. 6 Comparative acid nebulization and spark ablation background spectra (from $m / z=10$ to $m / z=80$ ).

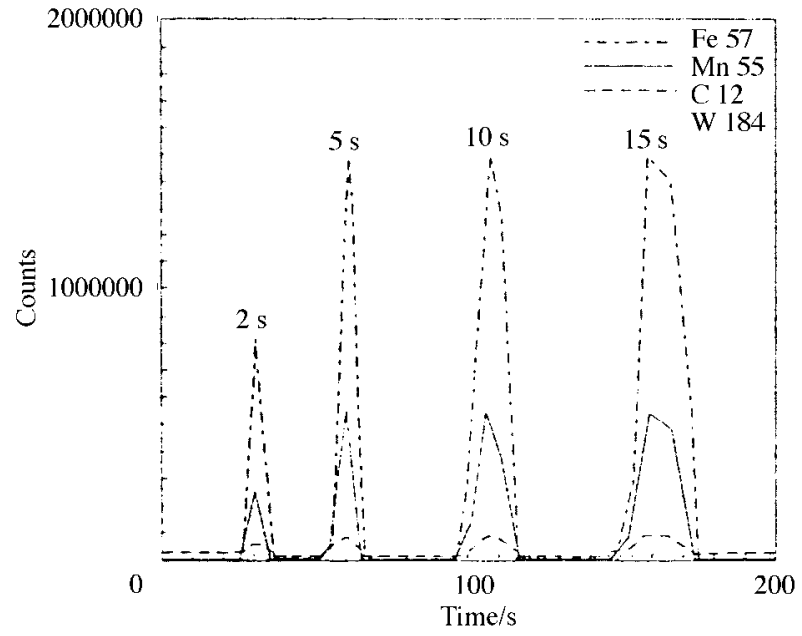

Fig. 7 Transient signals from sample C-305 with different sparking times $(2 \mathrm{~s}, 5 \mathrm{~s}, 10 \mathrm{~s}$ and $15 \mathrm{~s})$.

\section{Calibration graphs and analytical performance}

For the evaluation of the proposed method, calibration graphs including all the selected CRM were performed by applying function (1). To show the effectiveness of the use of an IS, C calibration graphs obtained without IS (plotting directly intensities versus concentrations) and with $\mathrm{Fe}$ and $\mathrm{Mn}$ as ISs are presented in Fig. 8 (A, B, C). These calibration graphs were directly provided by the ELAN 6000 software, the horizontal lines showing the difference between the measured intensity and its correct position according to the certified contents. The calibration concentration range is bounded by the lowest and the highest content of each element in the used CRM samples. The use of $\mathrm{Fe}$ or $\mathrm{Mn}$ as IS resulted in comparable correlation coefficients, values better than 0.999 always being found over the entire range of tested concentrations. Table 3 lists the parameters of the calibration graphs (according to the function $I_{\mathrm{X}} / I_{\mathrm{IS}}=\mathrm{f} C_{\mathrm{X}} / C_{\mathrm{IS}}$ ) for all analytes certified in the CRM, using $\mathrm{Fe}$ as IS for $\mathrm{Mn}$ and $\mathrm{Mn}$ as IS for the rest of the analytes. The high alloy steel CRM samples 285-2, 292-1, 2951 and 296-1 were analysed using the calibration graphs obtained with the low alloy steels series SS-456 to SS-460. The results found are listed in Table 4 and show a good agreement with the corresponding certified values. Calibration graphs could not be created for the elements W, As, Sn, Ti and Zr, because they are only certified in one or two of the CRMs. For these elements sensitivities were calculated from the ratio of the sample signal to the background signal (considering as background the signals provided by the pure iron sample
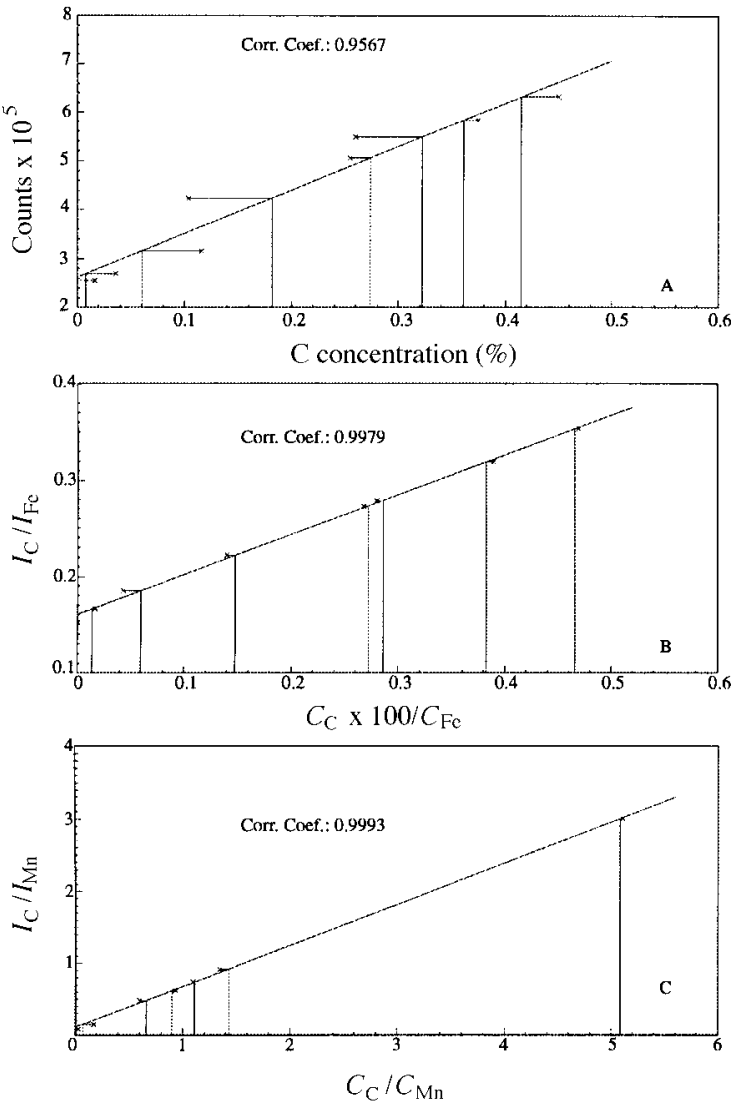

Fig. 8 Calibration curves for carbon: (A) without IS; (B) with Fe as IS; (C) with Mn as IS.

BAM-098/1) according to the function:

$$
S=I_{\mathrm{X}}-I_{\mathrm{B}} / C_{\mathrm{X}}
$$

where $I_{\mathrm{X}}$ is the intensity of the analyte in the sample, $I_{\mathrm{B}}$ the intensity of the analyte in the pure iron, and $C$ the concentration in $\mu \mathrm{g} \mathrm{g}^{-1}$ of the analyte in the sample. Table 5 lists these calculated sensitivity values, as well as the RSD values calculated from the standard deviation of the analyte intensities for $n=4$. Quantification limits (LOQ), considered as the concentration providing a signal of ten times the standard deviation of the signal intensities corresponding to the pure iron sample BAM CRM 098/1, were calculated from the slopes of the calibration graphs obtained by directly plotting intensities versus concentrations, or from the sensitivity values in the case of elements only certified in one or two of the CRMs. It should be mentioned that despite the high sensitivity of the 
Table 3 Calibration graph parameters using the function $I_{\mathrm{X}} / I_{\mathrm{IS}}=a C_{\mathrm{X}} / C_{\mathrm{IS}}+b: a=$ slope; $s_{a}=$ standard deviation of the slope; $b=$ intercept; $s_{b}=$ standard deviation of the intercept; $N_{\mathrm{s}}=$ number of standards used within each calibration procedure. ${ }^{57} \mathrm{Fe}$ was used as IS for Mn, and ${ }^{55} \mathrm{Mn}$ as IS for the rest of the analytes

\begin{tabular}{|c|c|c|c|c|c|c|}
\hline Isotope & $a$ & $s_{a}$ & $b$ & $s_{b}$ & $N_{\mathrm{s}}$ & Correlation coefficient \\
\hline${ }^{55} \mathrm{Mn}^{+}(\mathrm{Fe})$ & 73.5 & 1.0 & 1.7 & 1.4 & 10 & 0.99920 \\
\hline${ }^{11} \mathrm{~B}^{+}(\mathrm{Mn})$ & 0.90 & 0.01 & 0.001 & 0.0005 & 7 & 0.99978 \\
\hline${ }^{12} \mathrm{C}^{+}(\mathrm{Mn})$ & 0.73 & 0.014 & 0.093 & 0.027 & 8 & 0.99905 \\
\hline${ }^{27} \mathrm{~A}^{+}(\mathrm{Mn})$ & 33.25 & 0.50 & -0.32 & 0.15 & 8 & 0.99931 \\
\hline${ }^{28} \mathrm{Si}^{+}(\mathrm{Mn})$ & 5.58 & 0.061 & -0.45 & 0.14 & 10 & 0.99946 \\
\hline${ }^{31} \mathrm{P}^{+}(\mathrm{Mn})$ & 1.09 & 0.0091 & 0.0028 & 0.012 & 10 & 0.99982 \\
\hline${ }^{51} \mathrm{~V}^{+}(\mathrm{Mn})$ & 43.5 & 0.50 & -0.30 & 0.23 & 8 & 0.99965 \\
\hline${ }^{59} \mathrm{Co}^{+}(\mathrm{Mn})$ & 25.64 & 0.31 & -0.25 & 0.15 & 10 & 0.99924 \\
\hline${ }^{63} \mathrm{Cu}^{+}(\mathrm{Mn})$ & 9.11 & 0.13 & 0.10 & 0.050 & 5 & 0.99950 \\
\hline${ }^{93} \mathrm{Nb}^{+}(\mathrm{Mn})$ & 86.5 & 0.08 & 1.5 & 0.27 & 7 & 0.99933 \\
\hline
\end{tabular}

Table 4 Certified and found values $(\% \mathrm{~m} / \mathrm{m})$ for CRM high alloy steels

\begin{tabular}{|c|c|c|c|c|}
\hline Element sample & CRM 285-2 & CRM 292-1 & CRM 295-1 & CRM 296-1 \\
\hline Al cert. & $0.1067 \pm 0.0038$ & - & $0.0203 \pm 0.001$ & $0.0275 \pm 0.0019$ \\
\hline Al found & $0.101 \pm 0.003$ & - & $0.0190 \pm 0.0005$ & $0.0275 \pm 0.0007$ \\
\hline B cert. & $0.0009 \pm 0.0002$ & - & $0.0018 \pm 0.0001$ & - \\
\hline B found & $0.00088 \pm 0.00002$ & - & $0.00183 \pm 0.00003$ & - \\
\hline C cert. & $0.0018^{a}$ & $0.0367^{a}$ & $0.0018^{a}$ & $0.1166 \pm 0.0015$ \\
\hline $\mathrm{C}$ found & - & - & - & $0.1170 \pm 0.0025$ \\
\hline Co cert. & $7.7638^{b}$ & $0.0255 \pm 0.0023$ & $0.0450 \pm 0.002$ & $0.0218 \pm 0.0012$ \\
\hline Co found & - & $0.0263 \pm 0.0005$ & $0.0431 \pm 0.0008$ & $0.0199 \pm 0.0004$ \\
\hline $\mathrm{P}$ cert. & $0.0053^{a}$ & $0.0175 \pm 0.0014$ & $0.0167 \pm 0.0011$ & $0.0178 \pm 0.0007$ \\
\hline$P$ found & - & $0.0167 \pm 0.0001$ & $0.0168 \pm 0.0003$ & $0.0178 \pm 0.0002$ \\
\hline Si cert. & $0.0117 \pm 0.0017$ & $0.402 \pm 0.0104$ & $0.418 \pm 0.0175$ & $0.242 \pm 0.005$ \\
\hline Si found & $0.0135 \pm 0.0003$ & $0.390 \pm 0.007$ & $0.433 \pm 0.009$ & $0.230 \pm 0.004$ \\
\hline $\mathrm{V}$ cert & - & - & $0.0456 \pm 0.0033$ & $0.363 \pm 0.012$ \\
\hline $\mathrm{V}$ found & - & - & $0.0443 \pm 0.0005$ & $0.362 \pm 0.003$ \\
\hline
\end{tabular}

${ }^{a}$ Value lower than the lowest standard in the calibration curve (from SS-456 to SS-460). ${ }^{b}$ Value higher than the highest standard in the calibration curve (from SS-456 to SS-460).

Table 5 Sensitivity, expressed as $S=I_{\mathrm{X}}-I_{\mathrm{B}} / C_{\mathrm{X}}$, for the elements Ti, As, Zr, Sn, and W

\begin{tabular}{lcl}
\hline Isotope & Sensitivity/counts $\mu \mathrm{g}^{-1} \mathrm{~g}$ & $\operatorname{RSD}(n=4)$ \\
\hline${ }^{48} \mathrm{Ti}^{+}$ & 12954 & 2.02 \\
${ }^{75} \mathrm{As}^{+}$ & 530 & 0.57 \\
${ }^{90} \mathrm{Zr}^{+}$ & 13440 & 1.08 \\
${ }^{120} \mathrm{Sn}^{+}$ & 8778 & 0.30 \\
${ }^{184} \mathrm{~W}^{+}$ & 7800 & 1.59 \\
\hline
\end{tabular}

ICP-MS, no W contamination from the W electrode could be observed, this being in good agreement with the results obtained by Slickers ${ }^{17}$ using spark-AES. Table 6 shows the LOQ and the RSD values obtained for the samples with the lowest certified content values of the evaluated analyte, calcu-

Table 6 LOQ $\left(10 \times s_{\mathrm{b}}\right)$ and precision (RSD $n=4$, for the lowest certified value)

\begin{tabular}{|c|c|c|}
\hline Element & $\mathrm{LOQ} / \mu \mathrm{g} \mathrm{g}^{-1}$ & RSD (sample) \\
\hline $\mathrm{Al}$ & 0.55 & $2.8(\mathrm{SS}-457 / 1)$ \\
\hline As & 0.018 & $0.2(\mathrm{CRM} 295-1)$ \\
\hline B & 0.60 & $1.9(\mathrm{SS}-456 / 1)$ \\
\hline $\mathrm{C}$ & 250 & 1.9 (CRM 292-1) \\
\hline $\mathrm{Co}$ & 0.100 & $2.1(\mathrm{SS}-460 / 1)$ \\
\hline $\mathrm{Cu}$ & 0.20 & 0.75 (CRM 285-2) \\
\hline $\mathrm{Nb}$ & 0.020 & $2.3(\mathrm{C}-317)$ \\
\hline $\mathrm{P}$ & 2.0 & $0.56(\mathrm{CRM} 285-2)$ \\
\hline $\mathrm{Si}$ & 1.0 & 2.14 (CRM 285-2) \\
\hline $\mathrm{Sn}$ & 0.075 & $0.2($ CRM 295-1) \\
\hline $\mathrm{Ti}$ & 0.015 & 2.6 (CRM 285-2) \\
\hline V & 0.015 & $0.1(\mathrm{SS}-456 / 1)$ \\
\hline W & 0.055 & $1.6(\mathrm{C}-317)$ \\
\hline $\mathrm{Zr}$ & 0.010 & 1.1 (CRM 285-2) \\
\hline
\end{tabular}

lated from four repetitive sparkings at different locations on the sample.

\section{Conclusions}

The application of a unidirectional high current pulse spark has resulted in an effective sampling device for the ICP-MS bulk analysis of low and high alloy steels. The design of an appropriate restrictive path allowed a suitable degree of control of the uptake rate of aerosol reaching the plasma, providing at the same time good sensitivity and low drift and blockage effects. The use of the internal standard procedure for measurements, relating ratio intensities to ratio concentrations, permits the use of the same calibration curves for the analysis of different alloy grade steel samples. The linearity of response of the ratios makes it possible to obtain the calibration graph from only two calibration samples, bracketing the analyte concentration at both low and high ends. A precision better than 3\% (calculated at the lowest content tested for each analyte) has been obtained and limits of determination (on the basis of ten times the standard deviation of a pure iron sample) at the sub- $\mu \mathrm{g} \mathrm{g}^{-1}$ level can be calculated for the majority of the elements. The possibility of producing reproducible transient signals from discrete sampling processes has been shown. This process increases the sample throughput and the long-term stability. Solid sampling of limited sample quantities can be effective in minimising the risk of drift and instability associated with sample deposition on the sampling cone aperture. Further work relating to the use of transient signals for quantitative determinations in spark ablation ICP-MS will be carried out.

This work was supported financially by the European 
Community for Steel and Carbon (ECSC) and by the Comisión Interministerial de Ciencia y Tecnología (CICYT)

\section{References}

1 H. G. C. Human, R. H. Scott, A. R. Oakes and C. D. West, Analyst, 1976, 101, 265.

2 A. Aziz, J. A. C. Brokaert, K. Laqua and F. Leis, Spectrochim Acta, Part B, 1984, 39, 1091.

3 A. Lemarchand, G. Labarraque, P. Masson and J. A. C. Broekaert, J. Anal. At. Spectrom., 1987, 2, 481.

4 G. Vujicic and I. Steffan Microchim. Acta, 1990, 109, 315.

5 A. G. Coedo, T. Dorado, J. L. Jimenez and I. Gutierrez, J. Anal. At. Spectrom., 1992, 7, 11

6 C. Webb, C. S. Cooper III, A. T. Zander, J. T. Arnol, E. S. Lile and S. E. Anderson, J. Anal. At. Spectrom., 1994, 9, 263.

7 M. Gagean and J. M. Mermet, J. Anal. At. Spectrom., 1997, 12, 189.

8 S. J. Jiang and R. S. Houk, Anal. Chem., 1986, 58, 1739.

9 N. Jakubowski, I. Feldmann, B. Sack and D. Stuewer, J. Anal. At. Spectrom., 1992, 7, 121
10 K. A. Ivanovic, D. M. Coleman, F. W. Kunz and D. Schuetzle, Appl. Spectrosc., 1992, 46, 894

11 H.-M. Kuss, M. Müller, J. Petin, J. L. Jiménez Seco and K. Ohls, in Studium der Möglichkeiten und Probleme der ICP-MSAnalysentechnik in der Eisen- und Stahlindustrie, Bericht EUR 15994 DE, EGKS-EG-EAG, Brussels and Luxembourg, 1995, p. 78.

12 A. G. Coedo, T. Dorado and B. Fernandez, J. Anal. At. Spectrom. $1995, \mathbf{1 0}, 859$.

13 N. Jakubowski, I. Feldmann and D. Stuewer, Spectrochim. Acta, Part B, 50, 1995, 639.

14 O. V. Borisov, D. M. Coleman and R. O. Carter III, J. Anal. At. Spectrom., 1997, 12, 231.

15 K. E. Jarvis, A. L. Gray and R. S. Houk, Handbook of Inductively Coupled Plasma Mass Spectrometry, Blackie, London, 1992, p. 299.

16 Techniques de l'Ingenieur, P3 Analyse chimique caracterization, ISTRA BL, 1993, p. 2756.7.

$17 \mathrm{~K}$. Slickers, in Die automatische Atom-Emmissions-Spektralanalyse, ed. K. A. Slickers, Giessen, Germany, 2nd edn. 1992, p. 330 .

Paper 9/01650C 